\title{
VARIAÇÃO E LIVRO DIDÁTICO: PELOS CAMINHOS DA SOCIOLINGUÍSTICA EDUCACIONAL
}

\section{VARIATION AND TEXTBOOK: WAYS OF EDUCACIONAL SOCIOLINGUISTICS}

\author{
Eliane Vitorino de Moura Oliveira - UFAL Arapiraca ${ }^{1}$
}

\begin{abstract}
RESUMO
Tendo como fundamento a Sociolinguística Educacional, ou o propósito de enfrentar assertivamente os problemas educacionais e apresentar propostas pedagógicas concretas, apresento, neste trabalho, uma reflexão sobre a atuação dos materiais didáticos na promoção de uma consciência sobre a variabilidade da língua. A questão a ser respondida versa sobre o papel do livro didático na promoção de uma visão menos estereotipada da variação e na aceitação de nossa identidade linguística, problematizando sobre a premência de uma pedagogia voltada para a variação linguística, partindo de análises efetuadas em coleções de livros didáticos utilizados em escolas do norte do Paraná e do agreste Alagoano. O trabalho centra-se na análise de atividades com a temática da variação linguística inseridas em livros didáticos em três enfoques: i) materiais ainda em processo de elaboração; livros de coleções utilizadas em 2011; e, iii) livros de coleções à disposição das escolas em 2017. Para isso, alicerço-me em pesquisadores que se voltam para esse tema, como Bortoni-Ricardo (2014), Zilles e Faraco (2015), Almeida-Baronas e Cobucci (2016), entre outros, e têm desenvolvido importante discussão sobre a necessidade de uma abordagem menos estereotipada da variação; e que favoreça o entendimento da língua como um construto social, atualizada nas interações e, com isso, variada, heterogênea e rica.
\end{abstract}

PALAVRAS-CHAVE: Livros Didáticos; Pedagogia da Variação; Sociolinguística Educacional.

\begin{abstract}
Based on Educational Sociolinguistics, or the purpose of asserting facing educational problems and presenting concrete pedagogical proposals, I present in this work a reflection on the performance of didactic materials in the promotion of an awareness of the variability of the language. The question to be answered is the role of the textbook in promoting a less stereotyped view of variation and acceptance of our linguistic identity, thinking about the urgency of a pedagogy focused on linguistic variation, starting from analyzes carried out on collections of books used in schools in Paraná and in Alagoas. The work focuses on the analysis of activities with the theme of linguistic variation inserted in textbooks in three approaches: i) materials still in the process of elaboration; collection books used in 2011; and (iii) collection books available to schools in 2017. For that, I am based on researchers who turn to this theme, such as BortoniRicardo (2014), Zilles and Faraco (2015), Almeida-Baronas and Cobucci (2016), among others, and have developed an important discussion about the need for a less stereotyped approach to variation, and that favors the understanding of language as a social construct, updated in the interactions and, with it, varied, heterogeneous and rich.
\end{abstract}

KEYWORDS: Textbooks; Variation Pedagogy; Educational Sociolinguistics.

1 Doutora em Estudos da Linguagem pelo PPGEL/UEL. Email: liaoliver13@gmail.com eliane.oliveira@arapiraca.ufal.br 


\section{INTRODUÇÃO}

Este trabalho traz um olhar para o livro didático tendo a Sociolinguística Educacional como lente. De que maneira os materiais didáticos atuam no sentido de promover uma consciência sobre a variabilidade da língua? A questão a ser observada é se, como professores e professoras, temos o livro didático como um aliado na promoção de uma visão menos estereotipada da variação linguística? Esses materiais visam promover uma ampla discussão acerca de nossa "cara sociolinguística", usando um termo de Faraco (2014), ou reforçam visões restritas sobre a língua e, mais precisamente, sobre o ensino da língua?

Dito de outra maneira, partindo da visão da Sociolinguística Educacional que, como assevera Bortoni-Ricardo (2014, p. 1580) reflete o "esforço de aplicação dos resultados das pesquisas sociolinguísticas na solução de problemas educacionais e em propostas de trabalho pedagógicas mais efetivas", busco problematizar sobre a premência de uma pedagogia voltada para a variação linguística, partindo de análises efetuadas em coleções de livros didáticos utilizados nas escolas do Paraná e de Alagoas. Minha bandeira é, portanto, a da urgência de uma pedagogia da variação linguística, que se concretize desde os primeiros anos do ensino fundamental e se siga se ramificando e fortalecendo por todo a decorrer do ensino básico.

O trabalho centra-se na análise de atividades com a temática da variação linguística inseridas em livros didáticos de língua portuguesa, destinados ao ensino fundamental, em três enfoques: i) materiais ainda em processo de elaboração; ii) livros de coleções utilizadas em 2011, no Paraná; e, iii) livros de coleções a disposição das escolas de Alagoas, em 2017.

Em relação aos trabalhos em elaboração, as atividades analisadas referem-se a livros de uma editora do Paraná com a qual colaboro no sentido de analisar os exercícios propostos, indicando alterações, quando necessárias, para uma abordagem adequada da variação.

Nos livros didáticos do Paraná, trago um recorte de resultados obtidos a partir da participação no Projeto Variação Linguística na Escola, da Universidade Estadual de Londrina, focando em duas coleções: "Português: uma proposta de letramento", de Magda Soares, e "Aventura da Linguagem", de Luiz Carlos Travaglia, Maura Alves de Freitas Rocha e Vânia Maria Bernardes Arruda-Fernandes.

Já no que tange aos livros de Alagoas, apresento o resultado de análises empreendidas por alunos da disciplina Sociolinguística, ministrada no segundo semestre de 2017. A análise e a discussão parte das atividades dispostas nos livros da Coleção Conquista, de Maria Angela da Mota, material didático utilizado em escolas particulares de Arapiraca, capital do agreste alagoano. Também foi analisada a coleção Português: Linguagens, de William Roberto Cereja e Thereza Magalhães Cochar.

Para isso, alicerço-me em pesquisadores que se voltam para esse tema e têm desenvolvido importante discussão sobre a necessidade de uma abordagem menos estereotipada da variação, e que favoreça o entendimento da língua como um construto social, atualizada nas interações e, com isso, variada, heterogênea e rica.

$\mathrm{O}$ artigo se inicia com a reflexão sobre as atividades em elaboração; na sequência, apresenta a reflexão sobre os livros já publicados e disponíveis para os professores e professoras do ensino fundamental. Com isso em tela, um terceiro momento apresenta o posicionamento da Sociolinguística Educacional e as reflexões sobre a Pedagogia da Variação Linguística, ponderações que fundamentam minhas considerações finais.

No próximo item, trago resultados de análise em livros didáticos ainda em elaboração.

\section{A variação e o livro didático: em busca do tratamento ideal}

Mesmo que tenhamos hoje um tratamento mais adequado da variação linguística em sala de aula, há muito a ser alcançado. Há ainda muitas léguas a serem percorridas até alcançarmos o ideal - se é que o ideal um dia possa ser alcançado. 
Como lembram Zilles e Faraco (2015),

\begin{abstract}
"décadas de reflexão já resultaram em diretrizes que incorporam o estudo da variação linguística entre os temas do ensino de português e situam o trabalho com a expressão culta no interior do quadro mais amplo da variação linguística que caracteriza a nossa sociedade [entretanto, isso] "não conseguiu alterar substancialmente conceitos, atitudes e práticas, seja no geral da sociedade, seja no específico da educação (ZILLES e FARACO, 2015, p. 20)
\end{abstract}

Se, no senso comum, a realidade é conturbada para o tratamento da variação linguística, nas salas de aulas não há grandes progressos. Avançamos pouco, e há ainda os colegas de outras disciplinas que, sem tentar entender a questão, e muito menos ajudar a solucionar esse "problema", demonizam a variação e culpam os professores de língua portuguesa por aquilo que chamam de "empobrecimento da língua".

E, algo ainda mais preocupante, há entre nós mesmos, entre os professores de português, aqueles que continuam apresentando uma visão tradicional do ensino e praticando esse ensino.

Ainda que passos estejam sendo dados, incluindo aí a inserção da disciplina Sociolinguística em alguns cursos de Letras e a gênese de uma reflexão acerca da variação como constitutiva das línguas nas formações continuadas, os livros didáticos têm que acompanhar essa caminhada, visto serem materiais didáticos muito utilizados pelos professores em sua prática cotidiana, talvez os mais usados, tendo, com isso, um papel preponderante no que concerne ao tratamento da variação.

Em relação a isso, venho notando a busca por um tratamento menos folclorizado e menos superficial da variação por parte de autores de material didático ao dar assistência a trabalhos pontuais em editoras. Tenho verificado, com isso, a preocupação em atender às determinações oficiais expressadas em documentos como a Base Nacional Comum Curricular, os Parâmetros Curriculares Nacionais (BNCC), a fim de que o livro seja aprovado pelo Programa Nacional do Livro Didático. Apresento alguns exemplos para nossa reflexão e discussão².

Observei, em algumas dessas avaliações, momentos de acerto. Entre elas, cito uma atividade relacionada à variação histórica, na qual os autores partem de um anúncio publicitário de 1906 e outro de 1925 para trabalhar questões lexicais e sintáticas.

Quem trabalha com a variação há que concordar que aqui há um certo avanço, pois a maioria dos livros didáticos, quando tratam da variação histórica (Camacho, 1988), fazem-no a partir do poema "Antigamente" de Carlos Drummond de Andrade.

Outro exemplo de atividade adequada relaciona-se à variação estilística Para tratar desse tipo de variação, um livro didático dessa coleção revisada por mim traz um texto de um blogue, cuja linguagem é bastante informal, e questões sobre o uso formal e informal da língua, levando à reflexão sobre ambientes em que é possível se expressar com a variedade identitária e quando se faz mais apropriado um domínio maior das formas padrão da linguagem.

Em relação à variação regional, a utilização de cartas do Atlas Linguístico do Brasil (Cardoso et al, 2014) para tratar de variantes é, sem dúvida, um grande progresso trazido pela coleção analisada, pois, além de ser esse um dos objetivos principais do Atlas, o tema é tratado com cientificidade, com base em dados reais e abrangentes, saindo do senso comum.

Além disso, há a apresentação de um pequeno trecho do livro "Rosa do Riboque", de Albertino Bragança, no qual o diálogo dos personagens retrata o português falado em São Tomé e Príncipe. Divulgar uma variedade do português praticado na África e quase desconhecida, como é o falar de São Tomé e Príncipe, além de trabalhar com as competências linguísticas, ajuda a ampliar o conhecimento cultural dos alunos.

Já a abordagem da variação social, mais polêmica, não tem sido satisfatória também nesta coleção. Como exemplo, os autores, em um dos livros, para tratar da variação relacionada às questões socioculturais, propõem uma atividade que tem como instrumento $\Theta$ um poema de

\footnotetext{
${ }^{2}$ Os exemplos aqui apresentados são de materiais ainda em produção, por isso não há referências explícitas.
} 
Patativa do Assaré. Nela, solicitam ao aluno que explane as motivações do poeta para não realizar a concordância verbal de acordo com a norma padrão. Para auxiliar o professor na mediação da atividade, os autores apresentam uma nota, na qual explicam que a não-concordância se dá pelo fato de representar uma variedade típica de algumas regiões interioranas do Nordeste.

Aqui há um problema, pois a ausência da concordância verbal não é uma marca regional, muito menos uma variedade apenas de algumas regiões interioranas do Nordeste. Essa marca está no vizinho, no pai, até mesmo no próprio aluno - em algumas circunstâncias, no próprio professor. Para uma abordagem adequada, o ideal é mostrar a validade dessa forma de se expressar e, a partir disso, trabalhar com a ampliação da competência de quem tem essa "cara sociolinguística".

Outra consideração acerca dessa atividade se faz necessária. Ao formularem tal exercício, os autores entenderam que a proposta e as sugestões apresentadas em forma de nota para o professor seriam suficientes para levar os alunos a refletirem sobre a variação linguística, ou seja, que, com essa abordagem apenas, estaria amplamente contemplada a competência 4 descrita na BNCC, cujo teor é "4) Compreender o fenômeno da variação linguística, demonstrando atitude respeitosa diante de variedades linguísticas e rejeitando preconceitos linguísticos. (BRASIL, 2017, p. 85)". E não foi, como também não foram contemplados os itens 1 e 5 da Base, que especificam ser importante ao aluno:

1) Compreender a língua como fenômeno cultural, histórico, social, variável, heterogêneo e sensível aos contextos de uso, reconhecendo-a como meio de construção de identidades de seus usuários e da comunidade a que pertencem.

5) Empregar, nas interações sociais, a variedade e o estilo de linguagem adequados à situação comunicativa, ao(s) interlocutor(es) e ao gênero do discurso/gênero textual.

As atividades nos livros didáticos devem favorecer uma reflexão acerca da variação linguística, da legitimidade das variedades, da recorrência das variantes. Deve fazer pensar sobre o estigma, o preconceito, a identidade.

O trabalho com a variação social, em especial no nível sociocultural, é, muitas vezes, deixado à margem, porque, nesse contexto, o preconceito linguístico é mais visível - o que pode ser comprovado com toda a polêmica em torno do livro didático "Por uma vida melhor", de Carolina Maria Aguiar e outros, publicado em 2011 e distribuído pelo MEC aos alunos da EJA em 2012, mais precisamente, sobre o seguinte excerto:

\footnotetext{
“'Os livro ilustrado mais interessante estão emprestado.' Você pode estar se perguntando: mas eu posso falar 'os livro'. Claro que pode. Mas fique atento porque, dependendo da situação, você corre o risco de ser vítima de preconceito linguístico. Muita gente diz o que se deve e o que não se deve falar e escrever, tomando as regras estabelecidas para a norma culta como padrão de correção de todas as formas linguísticas. O falante, portanto, tem de ser capaz de usar a variante adequada da língua para cada ocasião.” (AGUIAR et alli, 2011. p. 16)
}

Este livro, que traz uma concepção até conservadora ao tratar da gramática, ousou tocar em uma ferida bastante purulenta, e que resultou num fervilhar de opiniões, em sua maioria leigas, vindas mormente da mídia jornalística, que visavam escrachar o livro - sobretudo, escrachar a variação linguística e, mais ainda, as pessoas que usam a variedade popular da língua, que falam "os livro" ao invés de "os livros".

Essa carência da variação social ou a inadequada abordagem desse tipo de variação nos livros didáticos não é fato novo. Pesquisas empreendidas no Projeto VALE - Variação linguística na Escola, desenvolvido na Universidade Estadual de Londrina pela professora Joyce Almeida Baronas e do qual eu faço parte (ALMEIDA-BARONAS, 2014), constataram tal deficiência, o que foi depois corroborado durante a disciplina de Sociolinguística, ofertada aos alunos como disciplina eletiva, no segundo semestre de 2017, no Curso de Letras Português da UFAL em Arapiraca, quando houve a análise de coleções utilizadas em Arapiraca e região por professores do Ensino Fundamental. 
Discorro a respeito dessas análises na sequência, olhando mais atentamente para o trabalho com a variação social.

\section{A variação e o livro didático: como acontece}

No projeto VALE, avaliamos as coleções de livros didáticos aprovados pelo PNLD e utilizados nas escolas do Paraná até 2012, utilizando a proposta de Camacho (1988) que classifica a variação em quatro tipos: geográfica, estilística, histórica e social.

Pela análise de 15 coleções, contando com 60 manuais, observou-se a supremacia do tratamento da variação estilística sobre as demais, já que aparece em 44 dos 60 manuais. A variação geográfica também é abordada, ainda que, na maioria das vezes, com base em estereótipos e apenas na questão lexical, apresentando-se na metade exata dos livros analisados.

A variação social e a variação histórica são as menos tratadas. Em apenas 45\% e 31,6\%, respectivamente, dos livros analisados, aparecem esses tipos de variação. ${ }^{3}$

Falando especificamente da variação social, somente 27 manuais abordaram esta variação, no que tange à sociocultura. Embora pareça um bom número, a análise mostrou que, dentre esses manuais, menos da metade apresenta uma abordagem adequada desse tipo de variação, o que nos remete à conclusão de Faraco (2015, p. 33), ou seja, que o tratamento dado à "variação social isto é, dos contrastes, conflitos, aproximações e distanciamentos entre as variedades do português chamado popular (a norma popular) e as variedades do português chamado culto (a norma culta/comum/standard)", é raro e, quando acontece, é maioritariamente insuficiente.

Destaco a análise realizada na coleção "Português: uma proposta de letramento", de Magda Soares, publicada em 2009, pela Editora Moderna, e em "Aventura da Linguagem", de Luiz Carlos Travaglia, Maura Alves de Freitas Rocha e Vânia Maria Bernardes Arruda-Fernandes, publicada em 2009, pela Editora Dimensão.

No livro de Soares, há um tratamento adequado da temática, mas não ainda suficiente. No livro do $6^{\circ}$ ano, há abordagem da variação estilística; além disso, o livro apresenta, nas instruções para o professor, uma sugestão para o trabalho da variação quanto à diferença etária sem, no entanto, trazer exercícios específicos para isso. No material destinado ao $7^{\circ}$ ano, há o trabalho com variação geográfica, trazendo termos específicos de regiões determinadas.

O livro do $8^{\circ}$ ano aborda todos os tipos de variação, mas de maneira um tanto superficial. Por exemplo, ao trazer o texto "Escrevo Brasileiro", de Mário de Andrade, abre um precedente para o trabalho com a variação cultural, em especial a questão da diferença entre a variedade popular e a norma culta aludida por Faraco (2015) e já mencionada neste trabalho. Entretanto, isso não acontece, pois as atividades seguem no sentido de trabalhar a diferença de registro coloquial e formal.

Com isso, percebe-se que apesar de abordar todos os tipos de variação, o trabalho com a variação sociocultural ainda é mínimo. Apenas o livro do $9^{\circ}$ ano traz uma atividade que aborda a variação social em nível cultural. Nela, os autores pedem aos alunos que releiam as seguintes frases retiradas de uma crônica presente no livro: "De português, não apreendem um pingalho" e "Sabe tênis e não sabe o idioma". Na sequência, orientam-nos a discutirem, com a condução do professor, sobre as seguintes questões:

\footnotetext{
"Quem não conhece as palavras como as citadas na crônica (ou como as que vocês usaram nos textos que produziram) não sabe português?”

. Saber português é conhecer palavras que ninguém diz?

. O que significa, realmente, saber português?
}

\footnotetext{
${ }^{3}$ Esses resultados e discussões sobre eles, além de detalhamento maior sobre o projeto VALE foram publicados por Almeida-Baronas, em 2014, e estão disponíveis para acesso em https://revistas.ufpr.br/abralin/article/view/38257/23356
} 
No livro de Travaglia, Rocha e Arruda-Fernandes, a análise também constatou o tratamento à variação linguística, tanto no manual para o professor, quanto nas atividades para os discentes. Há, com exceção do livro do $9^{\circ}$ ano, uma seção intitulada "Aprendendo mais sobre variação linguística". Com isso, todos os tipos de variação são abordados na coleção, mas a variação estilistica tem maior destaque, seguida da variação geográfica. Aparece, também, o trabalho com a variação histórica; a variação social é, mais uma vez, a menos abordada. Para que o trabalho seja bem direcionado, o Manual do Professor traz a seguinte instrução:

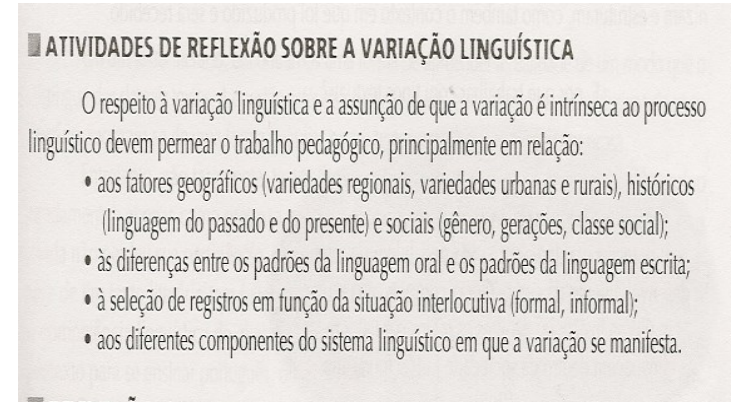

O interessante nesta coleção está nos vários momentos em que se poderia ser abordada a variação social. No livro do $7^{\circ}$ ano, por exemplo, há uma seção em que se trabalha o preconceito, sem que seja mencionado o preconceito linguístico.

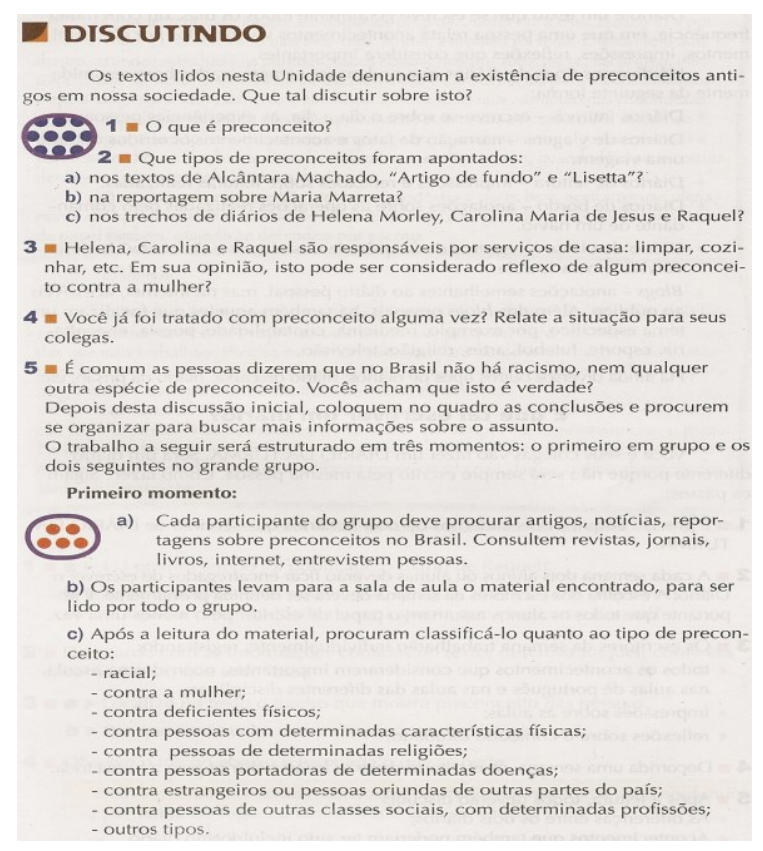

No livro do $9^{\circ}$, há temáticas que propiciariam trabalhar a diferente expressão linguística social e cultural, como uma unidade inteira que trata dos indígenas, e outra que fala da vida na terra, com capítulos intitulados "Homo Urbanus" e "Vida na cidade."

Entretanto, no livro destinado ao $8^{\circ}$ ano, a abordagem da variação linguística é adequada e relevante. As atividades conduzem os alunos a pensarem as diferenças linguísticas socioculturais como inerentes às linguas e possíveis de acordo com o gênero textual e o momento do discurso. Exemplifico com uma atividade do capítulo três em que, na interpretação textual, os autores questionam sobre a avaliação da variedade ao perguntarem "c) $\mathrm{O}$ autor considera feio o modo de falar de Falcote. Você concorda com o autor? Por quê?"

Foi o livro, em toda a análise promovida pelo Projeto, que mais abordou, e de maneira satisfatória, a variação social no nível sociocultural, como é possível observar nas imagens: 
6 = Observe os trechos a seguir:

(a) "Mas eu empino papagaio desde os tempos em que um papagaio era feito (a) Mas eu ép substantiva masculina) a afinar varetas com canivete e gilete azul."

b) "A gente somos especialistas em papagaio (e neste caso gente é plural; quando eu digo gente eu quero significar todos nós, os amofinados e os pingentes de gravata e pasta, os carapicus e os caras-de-gato)."

a $>$ Por que o autor diz que a gente, em (a), é palavra substantiva masculina e, em (b), gente é plural?

b > Você concorda com o autor quando ele diz que pode fazer esta distinção porque não é um gramático? Por quê? Resposta pessoal

7 - O autor diz que o cronista não é um gramático e que "Os gramáticos acham, e os gramáticos têm suas razões, que gente é uma palavra feminina e que deve concordar com o verbo no singular.".

a $>$ Você sabe o que faz um gramático? Caso não saiba, investigue o que faz um gramático, com seu professor, em dicionários, revistas, jornais, internet, gramáticas.

b \ Com base na resposta acima diga que razões os gramáticos teriam para fazer afirmações a respeito de empregos linguísticos.

$\mathbf{8}$ = Para empregar "a gente somos especialistas", o autor se justifica dizendo que não é um gramático. Mas depois corrige a fala do filho, dizendo: "- A gente nãc diz a gente podíamos. O certo é a gente podia competir".

Por que o autor não admite que o filho fale como ele?
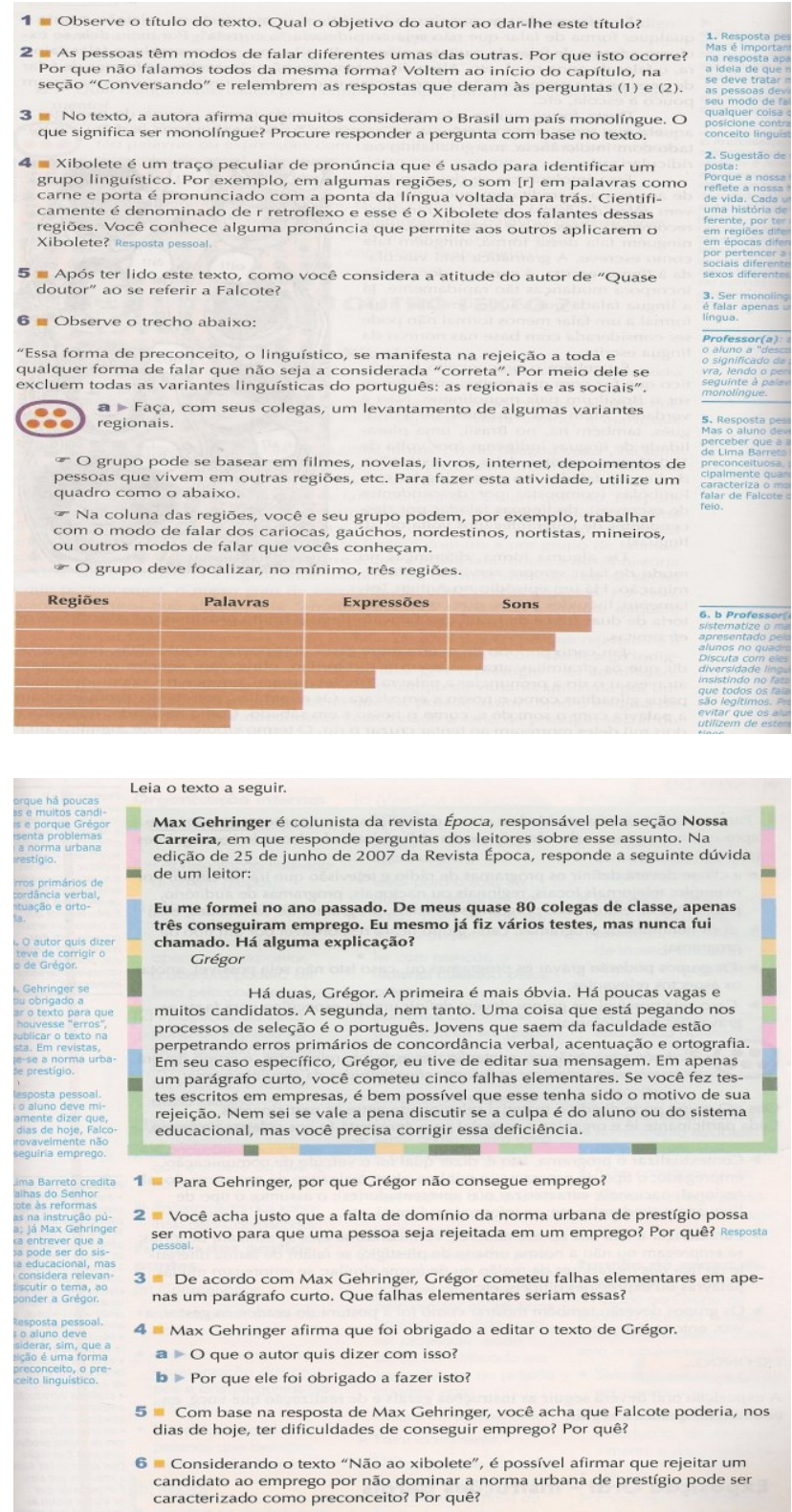
Essa análise foi realizada em 2013/2014. Na oportunidade, já havia o Programa Nacional do Livro Didático (PNLD), uma vez que avaliação dos livros didáticos data de 1937, com outras denominações. Dessa maneira, percebe-se que os autores aqui citados seguem as orientações do programa ao inserirem a discussão sobre a variabilidade da língua em seus materiais.

Em 2017, os alunos do Curso de Letras da Universidade Federal de Alagoas, no Campus Arapiraca, analisaram, também, os livros disponíveis para os professores na capital do agreste alagoano e região. Trago aqui apenas duas análises como exemplo do que foi encontrado. A primeira trata da abordagem da variação na Coleção Conquista, de Maria Angela da Mota, publicada pela Editora Positivo, utilizada em uma escola particular da cidade.

$\mathrm{Na}$ coleção, mais uma vez, o livro do $8^{\circ}$ ano apresentou o tema variação linguística explicitamente, sem, entretanto, tratar da variação sociocultural. Os demais livros não apresentaram, porém, as alunas ${ }^{4}$ que procederam à analise da coleção apontaram alguns momentos em que seria possível tal abordagem, como o livro do $6^{\circ}$ ano, que traz um texto, intitulado "O dia em que o matuto Zé Laurentino "tornou-se quipa", em que o falar rural/ rurbano é apresentado, sem que haja qualquer trabalho em relação ao isso.

Ainda nesta coleção, o livro do $7^{\circ}$ ano traz uma abordagem equivocada da variação, como se vê na imagem que segue:

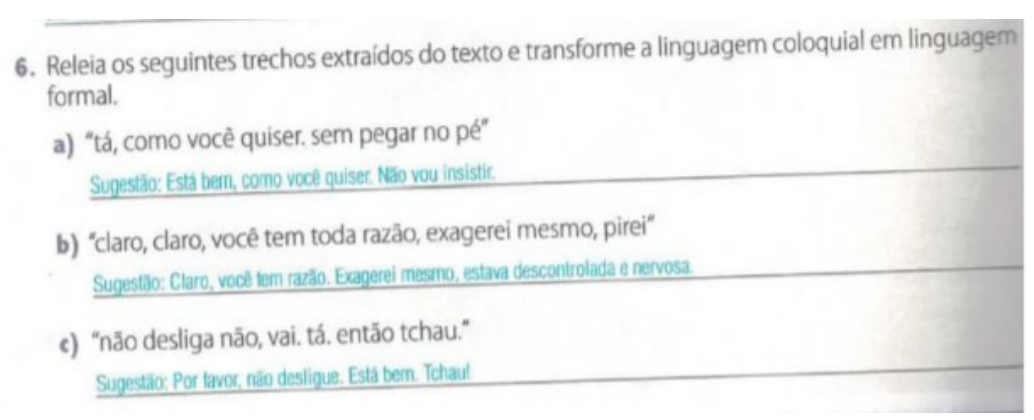

No exercício, os autores pedem que o aluno passe a fala o diálogo presente em uma tirinha de coloquial para formal. Ao invês de solicitar ao aluno que "transforme" uma variedade em outra, seria mais eficiente se a questão induzisse-o a perceber a diferença de contextos de uso da linguagem, e, com isso, capacitasse-o a transitar entre essas formas, mostrando que, na tirinha, está sendo retratada uma conversa entre amigos e, por isso, a uma forma coloquial. Assim sendo, a linguagem informal está adequada à interação comunicativa.

Para finalizar esta exemplificação, outro grupo ${ }^{5}$ de alunos analisou a $9^{a}$ edição da coleção Português: Linguagens, de William Roberto Cereja e Thereza Magalhães Cochar, publicada em 2015, pela Editora Saraiva.

A coleção traz a abordagem da variação de maneira explícita no livro do sexto ano, destacando variabilidade como algo natural e inerente a qualquer língua. O livro ainda menciona o preconceito linguístico, mas não há aprofundamento do tema. Há, ainda, o trabalho com a variação estilística e a geográfica. A variação sociocultural é abordada superficialmente e a variação histórica não chega a ser mencionada.

Nos demais livros da coleção, não há alusão ao tema. $\mathrm{Na}$ análise, os alunos perceberam momentos em que poderia ser discutida a variação, sem que isso acontecesse, entretanto. No livro do $8^{\circ}$ ano, que em outras coleções apresentou abordagem mais acurada sobre a temática, há

4 A análise foi realizada pelas alunas do 70 período do Curso de Letras Português da UFAL Arapiraca: Amanda Ferreira da Silva, Ana Arleide Oliveira Buarque de Gusmão, Natália Bezerra Maia de Albuquerque e Thereza Kardinally Barros Costa, na disciplina "Sociolinguística"

5 Análise realizada pelas alunas do 70 período do Curso de Letras Português da UFAL Arapiraca: Daniela de Souza Leite e Maraisa Alves Teles de Farias e pelos alunos especiais Aurélio Miguel da Rocha Vieira e Marílya Augusta Araújo Laurentino. 
momentos de trabalho com a variação estilística, porém de maneira superficial e isenta de uma conscientização sobre a efetivação diversificada da fala e da escrita em contextos variados.

No livro do $9^{\circ}$ ano, numa discussão sobre os sons da fala e a representação desses sons pela escrita, poderia ter havido um aprofundamento sobre a fala popular, principalmente em relação aos alçamentos de vogais, mas isso não acontece. A atividade explificada pela figura que segue, por exemplo, poderia ser um mote para esse apronudamento.

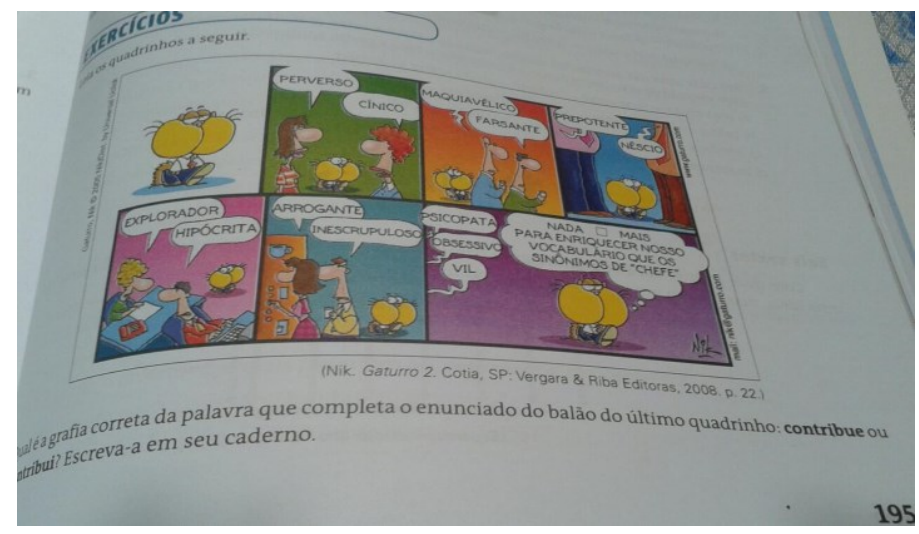

Percebemos, por essas reflexões, que os passos vêm sendo dados. Vagarosos, às vezes por descaminhos, mas os avanços vêm acontecendo. É necessário, no entanto, fortalecer o trabalho com a variação, sobretudo a sociocultural, para que haja entendimento e aceitação de nossa "cara sociolinguística", de nossa identitidade, de nossa brasilidade.

No tópico a seguir, falamos do papel e da importância da Sociolinguística Educacional nesse sentido.

\section{A Sociolinguistica Educacional e a pedagogia da variação linguística}

Percebam que esse tratamento adequado da variação linguística, os encaminhamentos para legitimar todas as variedades que comportam a nossa cara sociolinguística não significam a negação do acesso à expressão culta.

Como orienta Camacho (2011, p. 42)

[...] o indivíduo necessita ter, interiorizadas em sua competência linguística, as formas alternativas da variedade-padrão, ou de prestígio, e da variedade não-padrão, que pode também ser estigmatizada, sobre as quais ele pode operar seleção conforme variam as circunstâncias de interação. (CAMACHO, 2011, p. 42)

Essa capacidade de adequação só será possível por meio de atividades pedagógicas que oportunizem a ampliação da competência linguística dos alunos, atividades que levem em consideração a cara sociolinguística desses alunos. E se o livro didático é um dos instrumentos mais utilizados pelo professor para concretizar sua aula, nele deve haver um tratamento apropriado da variabilidade que constitui a língua.

Aliamo-nos a Castilho (2010, p. 209), quando compreende que,

tendo a escola a obrigação de ensinar o português culto, e levando em conta o ingresso nela de muitos alunos que praticam a variedade popular, é evidente que os professores têm de conhecer bem ambas as variedades para desenvolver estratégias de, respeitando a popular, expor os alunos à variedade culta. Ou seja, é preciso que professores e alunos conheçam bem ambas as variedades para escolher com adequação aquela que melhor corresponda à situação de fala: em casa, adota-se a norma familiar, qualquer que seja ela; falando com estranhos, adota-se o português padrão. É nessa espécie de 'bilinguismo interno', manejado com naturalidade em sociedades desenvolvidas, que se 
assenta uma percepção democrática de uso da língua materna. (CASTILHO, 2010, p. 209).

Esse é o papel da Sociolinguística Educacional, pois, como orienta Bortoni-Ricardo (2005, p. 128), a ela se referem "todas as propostas e pesquisas sociolinguísticas que tenham por objetivo contribuir para o aperfeiçoamento do processo educacional, principalmente na área do ensino de língua materna".

A autora, juntamente com Freitas (2009, p. 278) também trata dos objetivos dessa vertente ao pontuar que a Sociolinguística Educacional vem buscando construir métodos auxiliares aos professores, no sentido de ajudá-los a "desenvolver em seus alunos as habilidades cognitivas necessárias a uma aprendizagem mais ampla, à expansão de sua competência comunicativa e à capacidade de desenvolver tarefas escolares cotidianas, uma vez que busca respostas para as questões da escola dentro da escola, ou seja, no ambiente em que se dão, conciliando os processos macro e micro do processo de ensino e aprendizagem de língua materna.

Basicamente, como orienta Bortoni-Ricardo (2005), a Sociolinguística Educacional trabalha no sentido tornar clara a necessidade de uma pedagogia que se sensibilize com as diferenças linguistico-culturais dos alunos, o que, certamente, passa por uma mudança geral de postura: da escola, da família, dos alunos, da sociedade em geral.

É essa a metodologia ideal também para Cyranka (2016), quando reflete sobre o ensino e a aprendizagem de Língua Portuguesa. Em suas considerações, a autora caracteriza a Sociolinguística Educacional como a principal responsável em promover, em sala de aula, uma discussão que conscientize sobre a existência da variação linguística. Para ela, a Sociolinguística Educacional deve atuar o sentido de

\footnotetext{
levar para as salas de aula a discussão sobre a variação linguística, orientando os alunos a reconhecerem as diferenças dialetais e, mais importante, a compreenderem que essas diferenças dialetais são normais, legítimas e que devem ser consideradas na seleção das estruturas a serem utilizadas, a depender das condições de produção, isto é, das necessidades do leitor/escritor, falante/interlocutor, a partir do contexto em que se encontra. Desse modo, o conceito de "certo/errado" em linguagem é substituído pelo de "adequado/inadequado", o que predispõe os alunos ao desejo de ampliarem a competência comunicativa que já possuem, construindo crenças positivas sobre o conhecimento que têm de sua língua, no caso, a língua portuguesa. (CYRANKA, 2016, p. 169-170)
}

Para que tais considerações se tornem fato, Bortoni-Ricardo (2005) propõe seis princípios básicos a serem considerados quando se fala em ensino de língua materna pela escola: i) o trabalho com os estilos mais monitorados da língua; ii) observação do caráter sociossimbólico das regras variáveis, ou seja, a ênfase nas que recebem avaliação negativa; iii) inserção da variação sociolinguística na matriz social, viabilizando, com isso, a pedagogia culturalmente sensível (ERICKSON, 1987, P. 335, apud BORTONI-RICARDO, 2014); iv) a instituição da dicotomia oralidade/letramento, em que haja atenção aos estilos monitorados quando se tratar de eventos de letramento em sala de aula, ao passo que, em eventos de oralidade, a condução possa se dar em estilo mais casual; v) consideração dos valores e significados atribuídos à variação, em especial em relação à postura docente diante da variedade apresentada pelos alunos; vi) conscientização de alunos e professores no que tange à relação entre variação linguística e desigualdades sociais, a fim de promover o empoderamento do professor.

Essa discussão é ampliada por Almeida-Baronas e Cobucci (2016), quando refletem acerca da formação continuada de professores. Para as autoras, os professores devem prosseguir em sua jornada pedagógica, não se limitando aos conhecimentos adquiridos durante a graduação. É importante que sigam conhecendo novas formas de tratamento da língua, para que possam atuar eficientemente em sala de aula. 
Além disso, Almeida-Baronas e Cobucci (2016, p. 178) destacam a relação da Sociolinguística Educacional e os estudos sobre o letramento, quando conjeturam sobre a necessidade de "inserir o aluno num universo letrado, de forma que possa adquirir hábitos culturais desse universo", e, aqui, os recursos didáticos são fundamentais.

É importante esclarecer que tais condutas vêm se concretizando, ainda que morosamente, nas aulas de Língua Portuguesa a partir do $6^{\circ}$ ano do ensino fundamental, com uma consciência dos docentes e, também e, como vimos, ainda que timidamente, certa abordagem nos livros didáticos. O problema, entretanto, prende-se ao fato de não acontecer antes, ou seja, na gênese do ensino da língua a abordagem não se consuma.

Consoante tal realidade, faz-se necessário repensar o ensino de base. É mister perceber a importância da aplicação dos resultados da Sociolinguística na formação de professores alfabetizadores e daqueles que atuarão nas séries iniciais do ensino fundamental. Ou seja, é urgente que os cursos de Pedagogia aproveitem-se dos profícuos resultados da Sociolinguística na formação inicial e continuada de Pedagogos.

Bortoni-Ricardo (2005), com base nos resultados do Projeto Pontes, coordenado e conduzidor por ela na Faculdade de Educação da Universidade de Brasília por alguns anos, ao qual me integrei de 2010 a 2012, entende que a prática em sala de aula vem mostrando a importância de se levar em consideração os resultados dos estudos da sociolinguística para a educação, pois isso ajudará significantemente na melhoria na qualidade do ensino da língua materna em cursos de formação de professores alfabetizadores, porque trabalha com a língua em uso e considera os fenômenos linguísticos tendo como base a relação língua x sociedade e a realidade dos alunos.

Ou seja, é premente uma pedagogia da variação linguística que se insira na formação dos professores de língua portuguesa de todos os níveis de ensino e que permeie os materiais didáticos disponíveis para os profissionais. Uma pedagogia da variação linguística que, nas palavras de Faraco (2008, p. 180), não "escamoteie a realidade linguística do país (reconheça-o como multilíngue e dê destaque crítico à variação social do português); não dê um tratamento anedótico ou estereotipado aos fenômenos da variação."

Ainda de acordo com o pesquisador, é premente uma pedagogia que perceba a normapadrão como uma das variedades da língua, - não a única, não a verdadeira, não a certa, oportunizando e, mais que isso, estimulando a percepção da variação em todo seu potencial estilístico e retórico. "[...] Acima de tudo, uma pedagogia que sensibilize as crianças e os jovens para a variação, de tal modo que possamos combater os estigmas linguísticos, a violência simbólica, as exclusões sociais e culturais fundadas na diferença linguística." (Faraco, 2008, p. 180).

\section{CONSIDERAÇÕES FINAIS}

Eu vou me encaminhando para a conclusão dessas reminiscências, retomando um fato que circulou na internet há alguns anos, mais exatamente em março de 2014: camisetas foram distribuídas aos alunos do ensino médio em Brasilândia, no Distrito Federal, com uma palavra escrita fora das convenções ortográficas: encino por ensino. Tal fato levou, uma vez mais, a problemática do ensino de língua portuguesa à avaliação da mídia e ao julgamento dos leigos.

A questão que se apresenta é: por que essa camiseta saiu de uma empresa oficialmente ligada à Secretaria da Educação do Distrito Federal com problemas ortográficos? Desatenção? Fraude, como consideram Secretaria e Direção da Escola? Reflexo de um ensino problemático? Não é possível, no momento, saber. Sabe-se, no entanto, que alguém escreveu "ensino" com "c".

A retomada desse fato serve para reforçar, para levar-nos a concluir o protagonismo da escola na solução de um problema como esse, já que é seu papel apresentar ao aluno a variedade padrão da língua, pois é direito de todo cidadão ter acesso a qualquer forma de conhecimento, de bem cultural. 
É na escola, pelo uso de recursos e materiais didáticos adequados e eficientes, que o aluno reconhecerá que escrever 'encino', com c, é um desvio que deve ser evitado, uma vez que a palavra segue uma regra ortográfica fixa, não passível de variação.

É na escola, com o apoio irrestrito de seu material de estudo, que o aluno perceberá que falar "nós vai" é perfeitamente aceitável em determinadas situações, mas que ele pode, que é um direito seu o acesso às variadas maneiras de ampliação de sua competência linguista para que, com isso, seja capaz de passar a usar o "nós vamos" em situações cujo padrão seja exigido.

A escola precisa, portanto, favorecer o acesso a uma variedade diferenciada daquela que o aluno traz de casa, sem desmerecer e sem tentar substituir essa que lhe é identitária. Mas deve, sim, apresentar a variedade padrão, pois, na maioria dos casos, é somente em sala de aula que os alunos, falantes das variedades vernáculas, ou populares, podem ter acesso a esse tipo de bem cultural, útil para sua ascensão em diversos segmentos sociais. Para isso, uma pedagogia da variação linguística é de extrema importância.

Nós, Linguistas, Sociolinguistas, Professores de Língua Portuguesa e Pedagogos temos um papel importante a desempenhar em relação a essas questões tão complexas, polêmicas e controversas. E um dos caminhos para realizar esse papel eficientemente pode estar na Sociolinguística Educacional, na efetivação de uma pedagogia da variação linguística. Acredito nisso.

É difícil?

Fecho essa reflexão com a sensatez de Riobaldo Tatarana em Grande Sertão: Veredas, quando diz que "todo caminho da gente é resvaloso. Mas, também, cair não prejudica demais - a gente levanta, a gente sobe, a gente volta! Deus resvala? Mire e veja. Tenho medo? Não. Estou dando batalha." (Rosa, p. 440)

Sigamos dando batalha.

\section{REFERÊNCIAS}

AGUIAR, Carolina Amaral de et alli. Por uma vida melhor. Coleção "Viver, Aprender". Volume 2/Multidisciplinar. São Paulo: Editora Global, 2011.

ALMEIDA-BARONAS, Joyce Elaine. Variação linguística na escola: resultados de um projeto. Revista da ABRALIN, v.13, n.1, p. 39-62, jan./jun. 2014

ALMEIDA-BARONAS, Joyce Elaine; COBUCCI, Paula. A importância da sociolinguística educacional na formação docente continuada. IN.: MOLLICA, M.C.; FERRAREZI-JUNIOR, C. (org.) Sociolinguística, sociolinguísticas: uma introdução. São Paulo: Editora Contexto, 2016.

BORTONI-RICARDO, Stella Maris. Nós cheguemu na escola, e agora?: sociolinguística \& educação. São Paulo: Parábola Editorial, 2005.

Manual de Sociolinguística. São Paulo: Contexto, 2014.

BORTONI-RICARDO, Stella Maris; FREITAS, Vera Aparecida de Lucas. Sociolinguística Educacional. IN: Abralin: 40 anos em cena. João pessoa, Paraíba: Editora Universitária, 2009.

BRASIL. Ministério da Educação. Base Nacional Comum Curricular. Proposta preliminar. Segunda versão revista. Brasília: MEC, 2016. Disponível em: $<$ http://basenacionalcomum.mec.gov.br/documentos/bncc-2versao.revista.pdf $>$. Acesso em: 23.mai.2018. 
CAMACHO, Roberto Gomes. Norma culta e variedades linguísticas. In: Universidade Estadual Paulista. Prograd. Caderno de formação: formação de professores didática geral. São Paulo: Cultura Acadêmica, 2011, p. 34-49, v. 11. Disponível em: $<$ www.acervodigital.unesp.br/bitstream/123456789/40354/1/01d17t03.pdf>. Acesso em: 05.Mai.2018.

CARDOSO, Suzana Alice Marcelino da Silva; MOTA, Jacyra AndradE; AGUILERA, Vanderci de Andrade; ARAGÃO, Maria do Socorro Silva de; ISQUERDO, Aparecida Negri; RAZKY, Abdelhak; MARGOTTI, Felício Wessling; ALTENHOFEN, Cléo Vilson. Londrina: EDUEL, 2014.

CASTILHO, Ataliba T. de. Nova gramática da língua portuguesa. São Paulo: Contexto, 2010.

CYRANKA, Lucia. Sociolinguística aplicada à educação. IN.: MOLLICA, M.C.; FERRAREZIJUNIOR, C. (org.) Sociolinguística, sociolinguísticas: uma introdução. São Paulo: Editora Contexto, 2016.

FARACO, Carlos Alberto. Norma culta brasileira: desatando alguns nós. São Paulo: Parábola Editorial, 2008.

Norma culta brasileira: construção e ensino. In.: ZILLES, A.M.S.; FARACO, C.A. Pedagogia da variação linguística: língua, diversidade e ensino. São Paulo: Parábola Editorial, 2015.

ROSA, João Guimarães. Grande sertão: veredas. São Paulo: Editora Nova Aguillar, 1994. Disponível em <http://stoa.usp.br/carloshgn/files/-1/20292/ GrandeSertoVeredas GuimaresRosa.pdf.> Acesso em 03.Mai.2018

ZILLES, Ana Maria Stahl; FARACO, Carlos Alberto. Pedagogia da variação linguística: língua, diversidade e ensino. São Paulo: Parábola Editorial, 2015.

Submetido em 14/09/2018

Aceito em 01/11/2018 